GNIEWKO NiEdBAŁA ${ }^{1}$, TOMASZ LENARTOWICZ ${ }^{2}$, RADOSŁAW J. KOZŁOWSKI ${ }^{1}$, MACIEJ ZABOROWICZ ${ }^{1}$

${ }^{1}$ Instytut Inżynierii Biosystemów

Uniwersytet Przyrodniczy w Poznaniu

${ }^{2}$ Centralny Ośrodek Badania Odmian Roślin Uprawnych w Słupi Wielkiej

\title{
MODELOWANIE NEURONOWE
} JAKO METODA PROGNOZOWANIA ZAWARTOŚCI SKROBI W ZIEMNIAKACH NA POTRZEBY POREJESTROWEGO DOŚWIADCZALNICTWA ODMIANOWEGO I ROLNICZEGO (PDOIR)

\author{
NEURAL MODELLING AS A PREDICTION METHOD \\ OF STARCH CONTENT IN POTATOES FOR POST-REGISTRATION \\ AND SPECIFIC AGRICULTURAL EXPERIMENTATION
}

\begin{abstract}
Streszczenie. Istotną rolę w produkcji ziemniaków w Polsce odgrywa ich wartość przetwórcza i żywieniowa. Wśród uprawianych odmian ziemniaków wyróżniają się te, które cechują się dobrymi walorami kulinarnymi oraz parametrami technologicznymi korzystnymi w produkcji skrobi, frytek, chipsów, suszy itp. Znajomość najważniejszych cech użytkowych i biologicznych oraz wymagań agrotechnicznych ziemniaków pozwala na właściwy wybór odmiany dostosowanej do kierunku użytkowania, a tym samym do wymagań odbiorcy i rynku zbytu. Pomocne w wyborze odmiany mogą być wyniki uzyskane w ramach Porejestrowego Doświadczalnictwa Odmianowego i Rolniczego (PDOiR). Zmienność genotypowo-środowiskowa zakładanych na terenie całego kraju doświadczeń daje możliwość użycia sztucznych sieci neuronowych celem wytworzenia modelu, który pozwoliłby na predykcję zawartości skrobi w bulwach ziemniaków. Na podstawie zgromadzonych danych wytworzono model Sztucznej Sieci Neuronowej MLP 14 : 70-19-10-1 : 1, który z użyciem 14 niezależnych cech pozwala prognozować zawartość skrobi w poszczególnych odmianach ziemniaków.
\end{abstract}

Słowa kluczowe: zawartość skrobi, prognozowanie, modelowanie neuronowe 
Niedbała, G., Lenartowicz, T., Kozłowski, R. J., Zaborowicz, M. (2015). Modelowanie neuronowe jako metoda prognozowania zawartości skrobi w ziemniakach na potrzeby Porejestrowego Doświadczalnictwa Odmianowego i Rolniczego (PDOiR). Nauka Przyr. Technol., 9, 2, \#17. DOI: 10.17306/J.NPT.2015.2.17

\section{Wstęp}

Produkcja ziemniaków w Polsce posiada wieloletnie tradycje uprawowe oraz ma ogromne znaczenie gospodarcze. Na polskich stołach ziemniak jest podstawowym elementem żywieniowym, a także stanowi surowiec do produkcji chipsów i frytek. Jest to także roślina, dzięki której pozyskuje się skrobię dla celów przemysłowych.

Produkcja ziemniaków jest bardzo wyspecjalizowana i podlega ciągłym przemianom (Nowak i Kachel-Jakubowska, 2009). Zmiany systemów sadzenia, uprawy, zbioru, ochrony i nawożenia oraz pojawianie się na rynku nowych odmian tej rośliny powodują konieczność modyfikacji technologii produkcji (Kiełbasa, 2005; Zarzyńska i Wroniak, 2007). Optymalizacja produkcji w ujęciu jakościowym i ilościowym wymusza na producentach rolnych konieczność stosowania sprawdzonych rozwiązań, u których podstaw leżą wieloletnie doświadczenia rolników oraz wdrażane wyniki badań naukowych (Galdon i in., 2012; Jabłoński, 2012). Sprawdzenie aktualnej wartości gospodarczej starszych odmian znajdujących się w obrocie nasiennym oraz nowo wpisanych do Krajowego Rejestru (KR) jest głównym celem badań Porejestrowego Doświadczalnictwa Odmianowego i Rolniczego (PDOiR).

Celem pracy była budowa modelu, dzięki któremu możliwe będzie prognozowanie zawartości skrobi w ziemniakach. Do rozwiązania tego zadania wykorzystano Sztuczne Sieci Neuronowe (SSN) - jedno z narzędzi wykorzystywane w tego typu zagadnieniach (Dach i in., 2001; Niedbała i in., 2013). W celu wytworzenia modelu neuronowego, który umożliwiłby wykonywanie krótkoterminowych prognoz zawartości skrobi w ziemniakach, wykorzystano dane empiryczne pochodzące ze stacji doświadczalnych Centralnego Ośrodka Badań Odmian Roślin Uprawnych (COBORU). W trakcie realizacji celu pracy została wykonana analiza wrażliwości SSN, która umożliwiła określenie głównych czynników mających wpływ na prognozowanie zwartości skrobi w bulwach ziemniaków.

\section{Material i metody}

Pierwszym etapem realizacji badań było zebranie i opracowanie danych empirycznych z czterech stacji doświadczalnych COBORU: z Białogardu, Karżniczki, Kościelca, Krzyżewa (rys. 1). Do budowy modelu SSN wykorzystano dane pochodzące z badań prowadzonych na poletkach w latach 2004-2007. Każde z poletek, z którego dokonywano zbioru, miało powierzchnię $15 \mathrm{~m}^{2}$ (rys. 2).

Doświadczenia polowe wykonano w czterech powtórzeniach. Dla każdej z odmian każdorazowo zapisywano informację o sumie opadów w okresie wegetacji, wartości średniej temperatury powietrza, odległości roślin w rzędzie, terminie sadzenia i zbioru, kompleksie rolniczej przydatności gleby, jej odczynie $\mathrm{pH}$, poziomie nawożenia mineralnego azotem, fosforem i potasem. Zbierano także informacje o wschodach roślin oraz o terminie początku i pełni dojrzałości.

Budowa modelu neuronowego do wykonywania krótkoterminowych prognoz zawartości skrobi w ziemniakach została oparta na sieci typu Multilayer perceptron (MLP) posiadającej dwie warstwy ukryte (rys. 3). Na wejściu SSN zaprezentowano 14 nieza- 
Niedbała, G., Lenartowicz, T., Kozłowski, R. J., Zaborowicz, M. (2015). Modelowanie neuronowe jako metoda prognozowania zawartości skrobi w ziemniakach na potrzeby Porejestrowego Doświadczalnictwa Odmianowego i Rolniczego (PDOiR). Nauka Przyr. Technol., 9, 2, \#17. DOI: 10.17306/J.NPT.2015.2.17

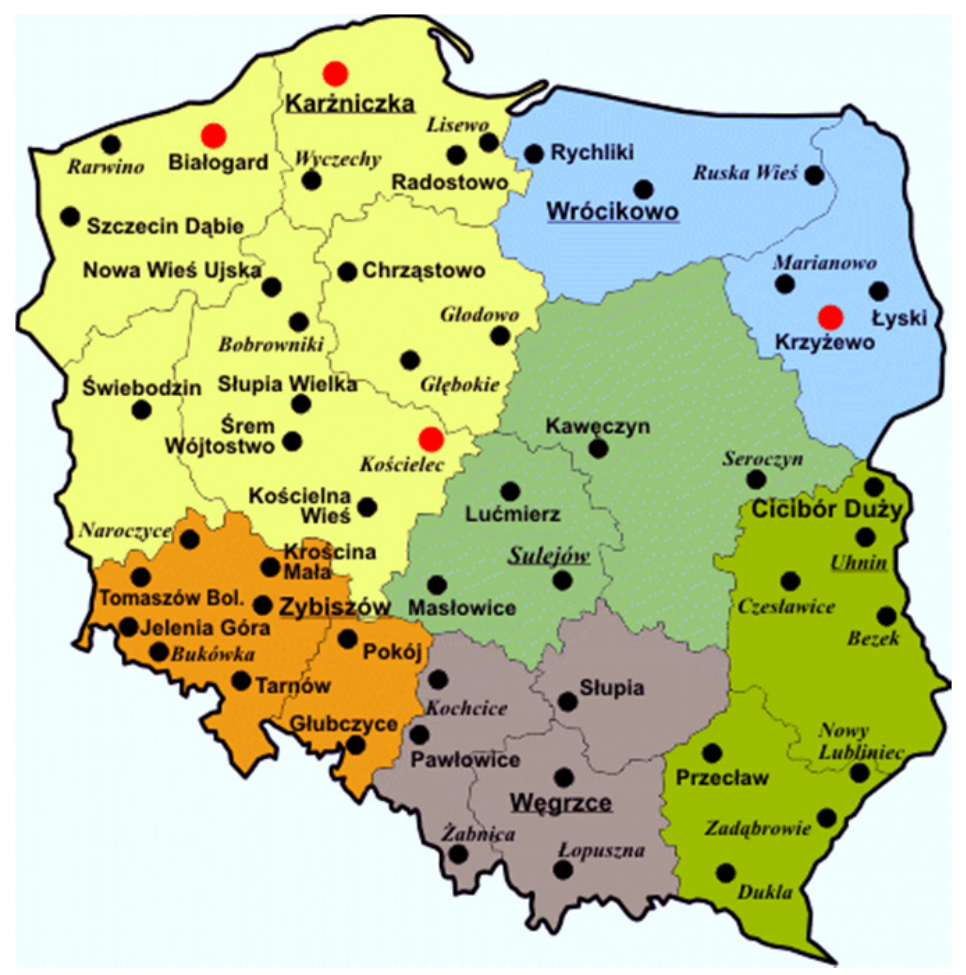

Rys. 1. Stacje Oceny Odmian COBORU oraz usytuowanie miejsc badań (Centralny...)

Fig. 1. Stations of Cultivars Assessment of The Research Centre for Cultivar Testing and location of research places (Centralny...)

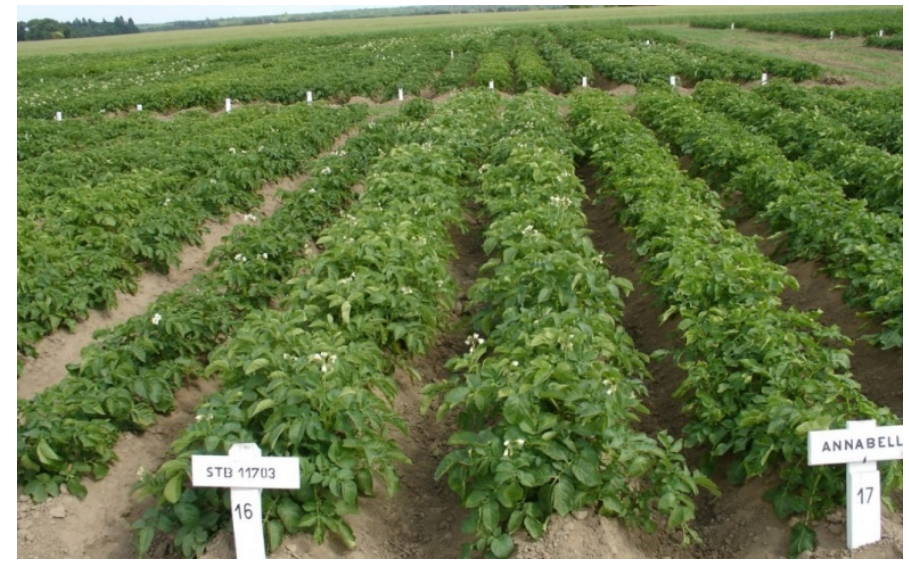

Rys. 2. Poletka doświadczalne

Fig. 2. Experimental plots 
Niedbała, G., Lenartowicz, T., Kozłowski, R. J., Zaborowicz, M. (2015). Modelowanie neuronowe jako metoda prognozowania zawartości skrobi w ziemniakach na potrzeby Porejestrowego Doświadczalnictwa Odmianowego i Rolniczego (PDOiR). Nauka Przyr. Technol., 9, 2, \#17. DOI: 10.17306/J.NPT.2015.2.17

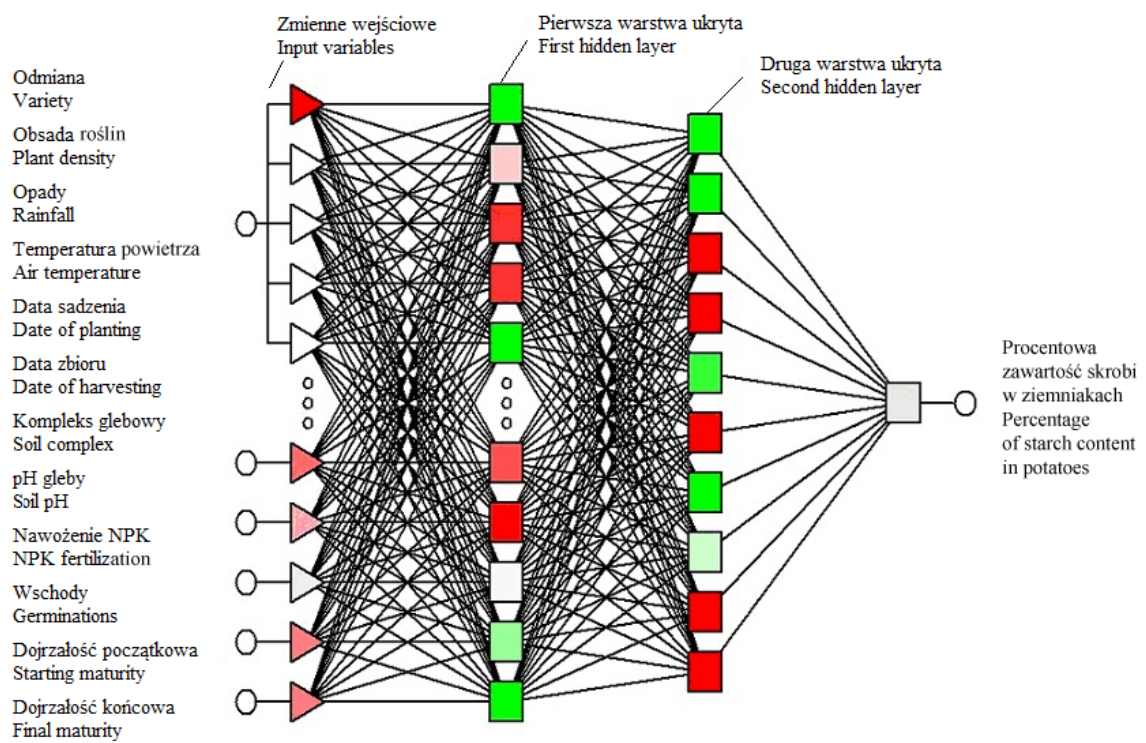

Rys. 3. Schemat sieci neuronowej typu MLP z dwiema warstwami ukrytymi dla prognozy zawartości skrobi w ziemniakach

Fig. 3. Diagram of MLP type neural network with two hidden layers for prediction of the starch content in potatoes

leżnych cech, takich jak: odmiana rejestrowa ziemniaka, suma opadów w okresie wegetacji, średnie temperatury powietrza zmierzone w okresie wegetacji, odległość roślin w rzędzie, termin sadzenia, termin zbioru, termin dojrzałości początkowej, termin wschodów, termin dojrzałości końcowej, kompleks rolniczej przydatności gleby, odczyn $\mathrm{pH}$ gleby, poziom nawożenia azotem, fosforem i potasem. W powyższym zestawie danych na wejściu sieci zaprezentowano jedną zmienną lingwistyczną - odmiana ziemniaka. W przeprowadzonych badaniach analizie poddano 56 odmian ziemniaków o zróżnicowanej wczesności plonowania. Wyjście modelu neuronowego stanowiła prognoza procentowej zawartości skrobi.

Do budowy modelu użyto 1716 przypadków. Zbiór danych został podzielony standardowo, według proporcji $50: 25: 25$, na trzy podzbiory: uczący (U) - 858 przypadków, walidacyjny (W) - 429 przypadków oraz testowy $(\mathrm{T})-429$ przypadków.

\section{Wyniki}

W trakcie prowadzonych badań zostały wytworzone i przetestowane modele neuronowe o różnych topologiach. Ze względu na parametry jakości sieci najlepszy okazał się perceptron wielowarstwowy MLP 14 : 70-19-10-1 : 1, który posiadał 14 zmiennych wejściowych, dwie warstwy ukryte, w których było odpowiednio 19 i 10 neuronów, oraz warstwę wyjściową z jedną zmienną. W trakcie przeprowadzania modelowania 
Niedbała, G., Lenartowicz, T., Kozłowski, R. J., Zaborowicz, M. (2015). Modelowanie neuronowe jako metoda prognozowania zawartości skrobi w ziemniakach na potrzeby Porejestrowego Doświadczalnictwa Odmianowego i Rolniczego (PDOiR). Nauka Przyr. Technol., 9, 2, \#17. DOI: 10.17306/J.NPT.2015.2.17

neuronowego wykonano analizę wrażliwości sieci, czyli analizę wpływu poszczególnych zmiennych wejściowych na działanie sieci, mającą wpływ na procentową zawartość skrobi (tab. 1). Przeprowadzenie analizy wrażliwości pozwoliło na jednoznaczną identyfikację głównych czynników odpowiedzialnych za gromadzenie skrobi w bulwach ziemniaków. Najważniejszą cechą okazała się odmiana rejestrowa ziemniaka (ranga 1.), poziom nawożenia mineralnego fosforem (ranga 2.) oraz średnie temperatury powietrza w okresie wegetacji (ranga 3.). Jednak wszystkie wykorzystane zmienne miały istotny wpływ na wytworzony model - prognozę zawartości skrobi.

Parametry jakościowe modelu neuronowego przedstawiono w tabeli 2.

Tabela 1. Analiza wrażliwości sieci neuronowych

Table 1. Sensitivity analysis of neural networks

\begin{tabular}{|l|c|c|}
\hline \multicolumn{1}{|c|}{ Zmienna - Variable } & Iloraz - Quotient & Ranga - Rank \\
\hline Odmiana - Variety & 7,54 & 2 \\
Fosfor - Phosphorus & 4,04 & 3 \\
Temperatura powietrza - Air temperature & 3,72 & 4 \\
Azot - Nitrogen & 2,24 & 5 \\
Data sadzenia - Date of planting & 2,16 & 6 \\
Kompleks glebowy - Soil complex & 2,06 & 7 \\
pH gleby - Soil pH & 2,01 & 8 \\
Potas - Potassium & 1,77 & 9 \\
Opady - Rainfall & 1,61 & 10 \\
Data zbioru - Date of harvesting & 1,53 & 11 \\
Dojrzałość początkowa - Starting maturity & 1,42 & 12 \\
Wschody - Germinations & 1,36 & 13 \\
Dojrzałość końcowa - Final maturity & 1,33 & 14 \\
Obsada roślin - Plant density & 1,01 & 7 \\
\hline
\end{tabular}

Tabela 2. Parametry jakościowe modelu neuronowego

Table 2. Quality parameters of neural model

\begin{tabular}{|c|c|c|c|}
\hline $\begin{array}{l}\text { Model SSN } \\
\text { ANN model }\end{array}$ & $\begin{array}{l}\text { Błąd uczący } \\
\text { Learning error }\end{array}$ & $\begin{array}{l}\text { Błąd walidacyjny } \\
\text { Validation error }\end{array}$ & $\begin{array}{l}\text { Błąd testowy } \\
\text { Test error }\end{array}$ \\
\hline $\begin{array}{l}\text { Sieć typu MLP - MLP network } \\
14: 70-19-10-1: 1\end{array}$ & 0,009740 & 0,22335 & 0,31177 \\
\hline
\end{tabular}


Niedbała, G., Lenartowicz, T., Kozłowski, R. J., Zaborowicz, M. (2015). Modelowanie neuronowe jako metoda prognozowania zawartości skrobi w ziemniakach na potrzeby Porejestrowego Doświadczalnictwa Odmianowego i Rolniczego (PDOiR). Nauka Przyr. Technol., 9, 2, \#17. DOI: 10.17306/J.NPT.2015.2.17

\section{Wnioski}

1. Sztuczne sieci neuronowe są przydatnym narzędziem w prognozowaniu zawartości skrobi w bulwach ziemniaków.

2. Siecią właściwą do prognozowania zawartości skrobi w ziemniakach jest sieć typu MLP $14:$ 70-19-10-1: 1 .

3. Najważniejszą zmienną niezależną spośród 14 zmiennych wejściowych okazała się odmiana ziemniaka.

4. Wygenerowany neuronowy model predykcyjny może stanowić podstawę budowy komputerowego programu wspomagania decyzji w prognozowaniu zawartości skrobi.

\section{Literatura}

Centralny Ośrodek Badania Odmian Roślin Uprawnych. Pozyskano z: http://www.coboru.pl [dostęp: 4.10.2013].

Dach, J., Niedbała, G., Przybył, J. (2001). Zastosowanie sieci neuronowych w rolnictwie. Inż. Roln., 1, 8, 57-62.

Galdon, B. R., Rodriguez, L. H., Mesa, D. R., Leon, H. L., Perez, N. L., Rodriguez, E. M. R., Romero, C. D. (2012). Differentiation of potato cultivars experimentally cultivated based on their chemical composition and by applying linear discriminant analysis. Food Chem., 133, 4, $1241-1248$.

Jabłoński, K. (2012). Nowoczesna produkcja ziemniaka w systemie rolnictwa integrowanego. Tech. Roln. Ogrodn. Leśn., 2, 10.

Kiełbasa, P. (2005). Ocena wybranych cech fizycznych bulw ziemniaków. Inż. Roln., 6, 66, $305-$ -313 .

Niedbała, G., Czechlowski, M., Wojciechowski, T. (2013). The use of artificial neural networks to predict the spatial variability of grain quality during combine harvest of wheat. J. Res. Appl. Agric. Eng., 58, 1, 126-129.

Nowak, J., Kachel-Jakubowska, M. (2009). Postęp w technologii uprawy ziemniaków i roślin okopowych. Tech. Roln. Ogrodn. Leśn., 2, 2-5.

Zarzyńska, K., Wroniak, J. (2007). Różnice w jakości plonu bulw ziemniaków uprawianych w systemie ekologicznym w zależności od niektórych czynników agrotechnicznych. J. Res. Appl. Agric. Eng., 52, 4, 108-113.

\section{NEURAL MODELLING AS A PREDICTION METHOD OF STARCH CONTENT IN POTATOES FOR POST-REGISTRATION AND SPECIFIC AGRICULTURAL EXPERIMENTATION}

Summary. Important role in the production of potatoes in Poland is played by their industrial and nutritional value. Among the cultivated potato varieties those that are characterized by a good culinary qualities and technological parameters for the production of starch, chips, crisps, dried, etc. are distinguished. Knowledge of the most important functional, biological and agronomic characteristic requirements allows for proper selection of varieties adapted to the direction of use, 
Niedbała, G., Lenartowicz, T., Kozłowski, R. J., Zaborowicz, M. (2015). Modelowanie neuronowe jako metoda prognozowania zawartości skrobi w ziemniakach na potrzeby Porejestrowego Doświadczalnictwa Odmianowego i Rolniczego (PDOiR). Nauka Przyr. Technol., 9, 2, \#17. DOI: 10.17306/J.NPT.2015.2.17

and thus to customer requirements and market outlets. Helpful, in the selection of varieties, can be results obtained from the Post-registration and Specific Agricultural Experimentation. The genotype-environment variability experiments, carried out all around the country, provide a possibility to apply Artificial Neural Network in the above work in order to generate a model enabling to predict the starch content in potato tubers. Based on the collected data, a model of Artificial Neural Network MLP $14: 70-19-10-1: 1$ was built. The model using 14 independent features enables predicting the starch content in different potato varieties.

Key words: starch content, forecasting, neural modelling

Adres do korespondencji-Corresponding address:

Gniewko Niedbała, Instytut Inżynierii Biosystemów, Uniwersytet Przyrodniczy w Poznaniu, ul. Wojska Polskiego 50,60-627 Poznań, Poland, e-mail: gniewko@up.poznan.pl

Zaakceptowano do opublikowania-Accepted for publication:

3.12.2014

Do cytowania - For citation:

Niedbała, G., Lenartowicz, T., Kozłowski, R. J., Zaborowicz, M. (2015). Modelowanie neuronowe jako metoda prognozowania zawartości skrobi w ziemniakach na potrzeby Porejestrowego Doświadczalnictwa Odmianowego i Rolniczego (PDOiR). Nauka Przyr. Technol., 9, 2, \#17. DOI: 10.17306/J.NPT.2015.2.17 